\title{
Nursing competence in Austria: Brightening the Black Box-A mixed methods study to estimate the content validity of the German version of the Nurse Professional Competence Scale
}

\author{
Jan Daniel Kellerer*1 ${ }^{*}$, Matthias Rohringer ${ }^{1}$, Isabella Raab ${ }^{2}$, Daniela Deufert ${ }^{1}$ \\ ${ }^{1}$ Department of Nursing Science \& Gerontology, UMIT - Private University for Health Sciences, Medical Informatics and \\ Technology, Austria \\ ${ }^{2}$ City Hospital Triemli, Zurich, Switzerland
}

Received: January 9, 2020

Accepted: February 17, 2020

Online Published: February 24, 2020

DOI: $10.5430 /$ jnep.v10n6p1

URL: https://doi.org/10.5430/jnep.v10n6p1

\begin{abstract}
The assessment of nursing-related competences by suitable instruments has become more relevant. Internationally, applicable instruments have been developed. The German-language version of the Nurse Professional Competence (NPC) Scale seems to be appropriate to measure competences of registered nurses in Austria. The psychometric properties of the scale have not been tested so far. The aim of this study was to examine the content validity of the German version of the NPC Scale. A mixed methods design was applied. Qualitative data were summarized by interpretative-reductive technique; the content validity index (CVI) was used to analyze the quantitative data. Data interpretation was performed by merging the results of the quantitative and qualitative analysis. As a result of the content analysis, five categories were determined to summarize the comments and critique. These categories referred to insufficient precision of terms and items, lacking profile-specific scale content to the theoretical construct of nursing-related competences, missing adequacy of the scale for the use in all nursing-related settings, and annotations for the revision of single items. Quantitative analysis showed 85 of 88 items as content valid by computing each single item. The dimension-specific CVI/Averages ranged between 0.90 and 0.97, the CVI/Average for the whole scale was 0.93. After merging the results of both qualitative and quantitative data analysis, the NPC Scale can actually not be evaluated as a content valid instrument for assessing nursing-related competences in an Austrian context. Substantial item-specific and dimension-specific deficiencies imply that competences cannot be thoroughly assessed. A substantial contentual revision of the current German version of the NPC Scale is recommended.
\end{abstract}

Key Words: Content validity, Psychometric testing, Mixed methods, Nursing competence, NPC Scale

\section{INTRODUCTION}

As demographic developments lead to an increasing life expectancy accompanied with age-dependent multimorbidity, societies focus the safeguarding of high-quality nursing. ${ }^{[1,2]}$
The legally defined specific qualification programs for different groups of nursing professionals imply varying competences deployed in patients' care. ${ }^{[3]}$ Making these competences visible supports the development of the occupational

\footnotetext{
* Correspondence: Jan Daniel Kellerer; Email: jan.kellerer@umit.at; Address: Department of Nursing Science \& Gerontology, UMIT - Private University for Health Sciences, Medical Informatics and Technology, Austria. 
group. ${ }^{[4]}$ The assessment of nurses' competences is as well essential for the evaluation and adaption of nursing qualification programs as is the appraisal of acquired competences in order to recognize prior learning and to facilitate access to academic education. ${ }^{[5]}$ Furthermore, international nursing mobility requires the possibility of determining employees' competences with country-specific demands. ${ }^{[6]}$ Although the need for standardized assessment of nursing competences is evident, there is still a lack of appropriate instruments for German-speaking countries. ${ }^{[7]}$

The number of definitions for nursing competences is widespread and there is no model generally applicable. ${ }^{[8]}$ The construct of nursing competence may not be perceived or defined exhaustively, even if several theories and concepts list single typical characteristics of nursing competencies or describe personal and contextual conditions for their development. ${ }^{[9,10]}$ Competence areas for assistant and registered nurses (RNs) in Austria are determined by the Act on nursing care, ${ }^{[11]}$ which is based on the referrals of the International Council of Nurses (ICN) - Nursing Care Continuum Framework and Competencies ${ }^{[12]}$ and taking Benner's and Olbrich's nursing competence models into account. ${ }^{[13]}$ In addition, professional, personal, social, communicative, and knowledge competencies are cited explicitly in the Austrian legal educational regulations for registered nurses. ${ }^{[14]}$

In order to assess nursing competencies in the Austrian nursing context adequately, an eligible instrument is needed. The Nurse Professional Competence (NPC) Scale ${ }^{[15]}$ was identified in a preceding literature research as substantively appropriate. ${ }^{[16]}$ This instrument was originally designed in Sweden for the quantitative self-assessment of individual nursing competencies. Its theoretical construct consists of eight dimensions (nursing care, value-based nursing care, medical/technical care, teaching/learning and support, documentation and information technology, legislation in nursing and safety planning, leadership in and development of nursing care, and education and supervision of staff/students), which are represented by 88 items in total. It was psychometrically tested in Sweden and translated into English. ${ }^{[17]}$ For the use in German speaking countries, the scale was translated into plain German language and afterwards culturally adapted for the cultural areas of Austria and Switzerland. ${ }^{[18]}$

In order to utilize a translated and culturally adapted instrument in the target language, its psychometric properties have to be tested. Therefore, an initial examination of the instrument's construct of its contentual validity is outlined as a minimal requirement for its acceptance. ${ }^{[19]}$ A test is contentual valid if (a) every item measures the property which it aims to assess concretely and precisely, (b) the item rep- resents the construct, ${ }^{[20]}$ (c) the item is relevant for the target population, ${ }^{[21]}$ (d) the construct is completely covered by the items, ${ }^{[22]}$ and (e) the construct is adjusted from irrelevant content. ${ }^{[23]}$ In regards to estimate these criterions adequately, different qualitative and quantitative approaches are suggested. ${ }^{[24]}$ Qualitative methods allow deeper insights regarding potential contentual critiques and comments, ${ }^{25]}$ whilst quantitative measures may constitute convenient methods to assess objective agreement among a various number of raters. ${ }^{[21,26]}$ Koller et al. ${ }^{[27]}$ suggest a mixed-methods-design, gathering data by formulating open content-related questions followed by a quantitative assessment of dimension-specific relevance of the items. Due to the high number of items representing different scale dimensions and with regard to an underlying theoretical construct that is not defined clearly nor predetermined conceptually, the use of qualitative and quantitative methods to estimate the content validity was approved.

The aim of this study was therefore to initially assess the content validity of the NPC Scale with regards to the Austrian nursing context.

\section{MeTHODS}

\subsection{Study design}

A mixed methods design (parallel triangulation design) was chosen to explore the scale's construct regarding content validity in depth and breadth. Results were interpreted by merging the qualitative and quantitative data.

\subsection{Estimating content validity quantitatively}

The Content Validity Index (CVI) ${ }^{[28]}$ is an established quantitative method to assess content validity in nursing science. Experts assess both the relevance of each single item for the instrument's theoretical construct and the adequacy and completeness of the set of items regarding the interested trait. The relevance of each item is initially assessed on a 4-point-Likert scale ( $1=$ not relevant, $2=$ somewhat relevant, $3=$ quite relevant, $4=$ highly relevant) by each expert. In a second step, ratings are dichotomized into two categories. "Not relevant" and "somewhat relevant" ratings are summed up by the category "not relevant" (relevance $=0$ ), whilst "quite relevant" and "highly relevant" ratings are pooled to the "relevant" category (relevance $=1$ ). In order to compute the content validity index on item-level (I-CVI), "relevant" ratings of the concerning item are summed up and divided by the total number of experts. I-CVI $\geq 0.78$ indicates excellent content validity under the premise that the number of raters is at least six. ${ }^{[29]}$ To examine the general content validity of an instrument, the calculation of the scale-level content validity index is suggested. Therefore, a) I-CVIs 
were summed up and divided by the number of items per scale dimension (so called "scale-dimension-level content validity index"/SD-CVI/Ave) to compute the content validity for each dimension separately, and b) the I-CVIs of all items featuring the instrument were added up and divided by the total number of items (scale-level content validity index/SSCI/Ave). SD-CVI/Ave und S-CVI/Ave $\geq 0.90$ establish excellent content validity. ${ }^{[30]}$

\subsection{Evaluating content validity qualitatively}

In order to contrast quantitatively estimated content validity, qualitative analysis of quoted comments was performed. An interpretative-reductive method ${ }^{[31]}$ is described as an adequate approach to create a synoptic corpus, which expresses the original material on a more abstract level. Adapting Mayring's general procedure model of qualitative content analysis, ${ }^{[32]}$ the material was defined and characteristically described before the direction of the analysis was chosen with regard to theoretical differentiation of sub-components of intended interest. In this study, theoretically substantiated sub-components concerned the aspects of item- and scalerelated content and varying aspects and definitions of nursing competencies. As the estimation of contentual relevance was a central focus in the context of testing content validity, the defined aspects in the meaning of this term were conductive in the analysis of the formulated raters' comments. Choosing a reductive model of content analysis, the stepwise process of paraphrasing, generalization on determined levels of abstraction, and an iterated reduction of coded analysis units led to inductively built categories. The resulting coding scheme was re-applied on the analysis material by a second researcher to ensure inter-coder reliability.

\subsection{Participants}

A non-probability purposing sampling method was chosen to ensure that the scale's theoretical construct relative to nurses' competencies in an Austrian context would be critically estimated from preferably varying experts' angles. Experts with different nursing-related professional backgrounds (nursing practice, nursing education, nursing management) were included. To avoid chance agreement among raters when using the CVI for estimating content validity, Beckstead ${ }^{[33]}$ suggests a minimum sample size of 35 experts. Consequently, a total number of 62 experts were initially invited to participate in the study. In Table 1, the inclusion criteria for experts are presented.

Table 1. Inclusion criteria for sample of experts

\begin{tabular}{|c|c|}
\hline CRITERION & EXPLICATION \\
\hline Experience of rater in clinical nursing practice & Rater has worked at least for 2 years in clinical nursing practice as RN \\
\hline $\begin{array}{l}\text { Professional education of rater in } \\
\text { clinical nursing practice }\end{array}$ & $\begin{array}{l}\text { Rater has at least successfully completed either three-years scholastic or } \\
\text { academic vocational nursing program in Austria }\end{array}$ \\
\hline $\begin{array}{l}\text { Professional education of rater in professional area } \\
\text { of nursing management }\end{array}$ & $\begin{array}{l}\text { Rater has the credentials defined by Austrian law to function as a nursing } \\
\text { manager }\end{array}$ \\
\hline $\begin{array}{l}\text { Professional education of rater in professional area } \\
\text { of nursing education }\end{array}$ & $\begin{array}{l}\text { Rater has the credentials defined by Austrian law to function as a nursing } \\
\text { educator }\end{array}$ \\
\hline Language & Rater speaks the German language fluently \\
\hline
\end{tabular}

\subsection{Data collection and questionnaire}

Every expert was informed by a detailed written description about the aim of the study and the voluntariness of participation. The questionnaire consisted of three parts. The first part comprised the 88 items of the NPC Scale. A 4-point-Likert scale $(1=$ not relevant, 2 = somewhat relevant, $3=$ quite relevant, 4 = highly relevant) to estimate relevance quantitatively was appended to each item. A free-text window was also applied to each single item in the questionnaire and raters were advised to optionally amend their quantitative estimation with critical comments. The second part of the questionnaire included three questions concerning both quantitative and qualitative summative judgement a) of the instrument's ability to cover nurses' competencies exhaustively, b) of missing aspects of nursing competence not covered by the instru- ment and c) of the comprehensibility of the NPC Scale. Part three gathered socio-demographic and profession-related information (age, gender, professional experience in nursing practice, current professional area of activity, and experience in current professional area of activity).

\subsection{Ethical considerations}

According to the estimation of the Research Committee for Scientific and Ethical Questions (RCSEQ) of UMIT-Private University of Health Sciences, Medical Informatics and Technology, Hall in Tyrol, ethical appraisal has not been necessary. Raters participated voluntarily in the study and written informed consent was obtained prior to participation. 


\section{Results}

A total of 62 nursing professionals were asked to participate in the study as experts, finally 49 returned the completed questionnaire (response rate $=79.0 \%$ ). Approximately two thirds of the participants were female, average age hardly differed between genders, neither in the total sample nor in the subgroups. Nearly half of the sample was represented by nursing educators, this subgroup had the highest genderspanning average age and the highest average professional experience, both in nursing practice and in their current activity field (see Table 2).

Table 2. Socio-demographic analysis of the sample

\begin{tabular}{|c|c|c|c|c|c|c|}
\hline $\begin{array}{l}\text { Current } \\
\text { activity area }\end{array}$ & Gender & Sample & & $\begin{array}{l}\text { Age } \\
\text { (years, Mean } \pm \text { SD) }\end{array}$ & $\begin{array}{l}\text { Experience in } \\
\text { nursing practice } \\
\text { (years, Mean } \pm \text { SD) }\end{array}$ & $\begin{array}{l}\text { Experience in } \\
\text { current activity area } \\
\text { (years, Mean } \pm \text { SD) }\end{array}$ \\
\hline \multirow{3}{*}{$\begin{array}{l}\text { Nursing } \\
\text { Practice }\end{array}$} & Female & $\mathrm{n}=11$ & $(78.6 \%)$ & $30.9 \pm 4.48$ & $8.2 \pm 4.2^{*}$ & $4.7 \pm 2.7^{*}$ \\
\hline & Male & $\mathrm{n}=3$ & (21.4\%) & $29.3 \pm 5.86$ & $9.7 \pm 7.5$ & $7.7 \pm 6.0$ \\
\hline & Total & $\mathrm{n}=14$ & $(100 \%)$ & $30.6 \pm 4.6$ & $8.5 \pm 4.8^{*}$ & $5.4 \pm 3.7^{*}$ \\
\hline \multirow{3}{*}{$\begin{array}{l}\text { Nursing } \\
\text { Education }\end{array}$} & Female & $\mathrm{n}=14$ & $(63.6 \%)$ & $44.6 \pm 9.5$ & $12.2 \pm 8.8$ & $9.6 \pm 8.5$ \\
\hline & Male & $\mathrm{n}=8$ & $(36.4 \%)$ & $49.0 \pm 9.9 *$ & $21.6 \pm 13.9 *$ & $13.3 \pm 8.6$ \\
\hline & Total & $\mathrm{n}=22 *$ & $(100 \%)^{*}$ & $46.1 \pm 9.6^{*}$ & $15.5 \pm 11.4^{* *}$ & $10.9 \pm 8.5^{*}$ \\
\hline \multirow{3}{*}{$\begin{array}{l}\text { Nursing } \\
\text { Management }\end{array}$} & Female & $\mathrm{n}=8$ & $(66.7 \%)$ & $34.3 \pm 7.2$ & $11.2 \pm 4.3$ & $3.0 \pm 2.7$ \\
\hline & Male & $\mathrm{n}=4$ & (33.3\%) & $34.5 \pm 8.3$ & $13.1 \pm 9.3$ & $5.6 \pm 7.6$ \\
\hline & Total & $\mathrm{n}=12$ & $(100 \%)$ & $34.3 \pm 7.2$ & $11.9 \pm 6.0$ & $3.9 \pm 4.7$ \\
\hline \multirow{3}{*}{ All areas } & Female & $\mathrm{n}=33$ & (68.8\%) & $37.6 \pm 9.7$ & $10.6 \pm 6.6^{* *}$ & $6.5 \pm 6.5^{*}$ \\
\hline & Male & $\mathrm{n}=15$ & (31.2\%) & $40.6 \pm 12.1^{*}$ & $16.6 \pm 12.0^{*}$ & $9.9 \pm 8.1^{*}$ \\
\hline & TOTAL & $n=49$ & $(100 \%)$ & $38.5 \pm 10.4^{*}$ & $12.5 \pm 9.0 * * *$ & $7.5 \pm 7.1^{* *}$ \\
\hline
\end{tabular}

*missing: $\mathrm{n}=1$; **missing: $\mathrm{n}=2$; ***missing: $\mathrm{n}=3$

In Table 2, information about participants' characteristics is outlined with respect to both the sample in total and the defined subgroups. Analysis of item-level content validity (I-CVI-scores) showed 85 of 88 assessed items reaching the predefined cut-off-score of at least 0.78 (range $=0.79-1.00$ ) Item 59 ("Do you think you have the ability to act from an environmentally conscious perspective"; I-CVI =0.76), item 61 ("Do you think you have the ability to safeguard aesthetic aspects of the care environment?"; I-CVI =0.71), and item 78 ("Do you think you have the ability to promote patientfocused nursing care in a cost-conscious manner?"; I-CVI = 0.69 ) fell below the intended cut-off-score of at least 0.78 . These three items are all assigned to scale-dimension 7.

The scale's dimension-specific content validity indices (SDCVI/Ave) ranged from 0.90 ("Dimension 7: Leadership in and development of nursing") to 0.97 ("Dimension 5: Documentation and information technology"), the scale-level content validity index (S-CVI/Ave) was 0.93 (cut-off score for both SD-CVI/Ave and S-CVI/Ave $\geq 0.90$ ).

The content analysis of 138 comments and annotations led to five main categories summing up the original material on a more abstract level. Category 1 "Critique on the precision of term" was represented by 25 analysis units, which criticised missing accuracy, clearness, or distinctness of single terms. The 30 analysis units dedicated to category 2 "Critique on the precision of item" criticised the item in general regarding to its formulation or missing semantic or contextual significance. 47 analysis units, which pointed out missing concordance between competences mentioned in the NPC Scale and the Austrian Act on nursing care, were related to "Critique on the relevance for the professional profile" (category 3). Summing up 23 statements with concern to competencies, which were estimated as not equally relevant for all nurses due to different organisational, structural, setting-specific, or legal conditions, category 4 was defined as "Critique on the relevance related to different surrounding conditions". Finally, category 5 ("Proposals for re-formulations and extensions of items") summarized 13 concrete suggestions formulated by raters for revision of single items.

In total, experts estimated the instrument's ability to cover nurses' competencies exhaustively either as absolutely or at least quite given. Most of the raters negated the question concerning missing aspects of nursing competence not covered by the instrument, and the NPC Scale was judged as absolutely or quite comprehensive (see Table 3). 
Table 3. Results of the summative evaluation of the NPC Scale

\begin{tabular}{|c|c|c|c|c|c|c|c|}
\hline & Summative estimation aspect & $\begin{array}{l}\text { Raters } \\
\text { N (\%) }\end{array}$ & $\begin{array}{l}\text { Yes\# } \\
\text { N (\%) }\end{array}$ & $\begin{array}{l}\text { Fair to } \\
\text { yes }^{\#} \\
\text { N (\%) }\end{array}$ & $\begin{array}{l}\text { Fair to } \\
\text { no }^{\#} \\
\text { N (\%) }\end{array}$ & $\begin{array}{l}\text { No\# } \\
\text { N (\%) }\end{array}$ & Median \\
\hline 1 & $\begin{array}{l}\text { Are the } 88 \text { items of the NPC Scale able to cover up } \\
\text { nurses' competencies exhaustively? }\end{array}$ & $\begin{array}{l}49 \\
(100)\end{array}$ & $\begin{array}{l}36 \\
(73.5)\end{array}$ & $\begin{array}{l}13 \\
(26.5)\end{array}$ & --- & --- & 1 \\
\hline 2 & $\begin{array}{l}\text { Are there any relevant aspects of nursing } \\
\text { competencies that are not covered by the instrument? }\end{array}$ & $\begin{array}{l}49 \\
(100)\end{array}$ & $\begin{array}{l}3 \\
(6.1)\end{array}$ & $\begin{array}{l}2 \\
(4.1)\end{array}$ & $\begin{array}{l}24 \\
(49.0)\end{array}$ & $\begin{array}{l}20 \\
(40.8)\end{array}$ & 3 \\
\hline 3 & Is the NPC Scale comprehensible? & $\begin{array}{l}49 \\
(100)\end{array}$ & $\begin{array}{l}33 \\
(67.3)\end{array}$ & $\begin{array}{l}15 \\
(30.6)\end{array}$ & $\begin{array}{l}1 \\
(2.0)\end{array}$ & --- & 1 \\
\hline
\end{tabular}

\# Likert-scaling: 1 = yes, 2 = fair to yes, 3 = fair to no, 4 = no

Figure 1 gives a detailed overview of the merged quantitative and qualitative results pointing out the S-CVI/Ave for the total NPC scale, eight SD-CVI/Ave scores including their re- lating I-CVI ranges, and the dimension-specific distributions of categorized analysis units.

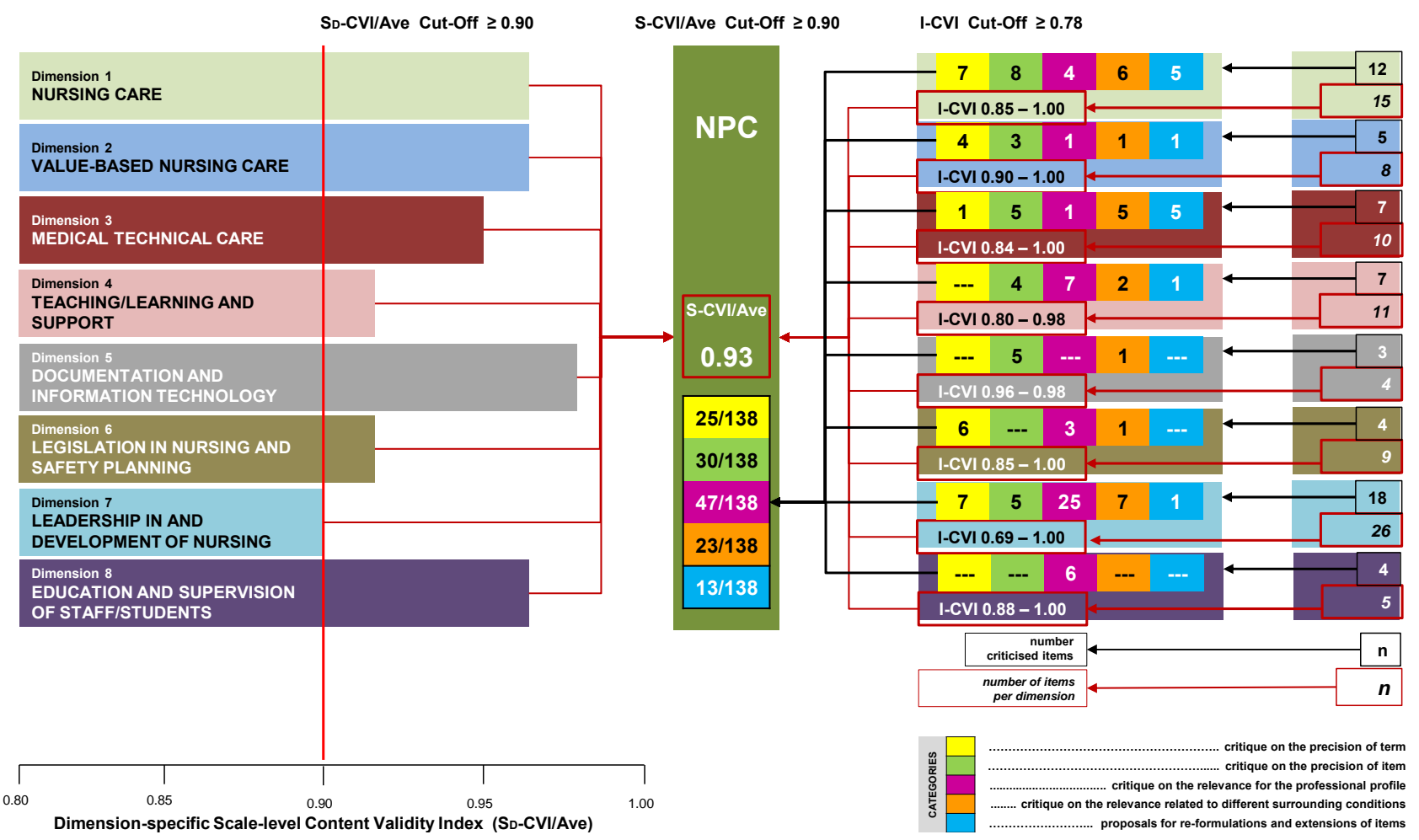

Figure 1. Merged results of qualitative and quantitative assessment of the NPC Scale

\section{Discussion}

The aim of this study was to explore the content validity of the NPC Scale from different angles by using quantitative and qualitative approaches. Results of the quantitative analysis showed excellent content validity indices both for the NPC Scale generally and its eight scale dimensions. On item-level, 85 of 88 items could be shown as content valid, three items failed the determined cut-off. 138 annotations were assigned to five inductively constructed categories, including critique concerning the precision of terms and items, unclear rele- vance of item content with relation to professional profiles or surrounding conditions, and proposals for item revision. The NPC Scale was estimated as an eligible and comprehensive instrument to cover nurses' competencies, although some relevant aspects of nursing competencies might be missing.

31 Items assigned to six different scale dimensions were criticised in regards to insufficient precision of single terms (25 analysis units distributed over scale dimensions 1, 2, 3, 6, and 7) or of the item in general (30 analysis units concerning scale dimensions 1, 2, 3, 4, 5, and 7). Bühner ${ }^{[20]}$ states that 
content validity may be assumed if every single item seizes the measurable trait truly and precisely. Taking into account that in total 55 statements doubted the precision, accuracy, clarity, or distinctness of terms or items, content validity could not be interpreted as given on the basis of the qualitative results. Approximatively one third $(n=47 / 138)$ of all stated comments were summed up to the category critique on the relevance for the professional profile. A proportionally high number $(n=21)$ of these critical annotations was found in scale-dimension 7 , which contains requests on nursing leadership and development competencies. In fact, 13 of 26 items regarding dimension-specific competencies were estimated as not necessarily representing RNs' competencies. Even if "leadership and management" is represented as a sub-domain of care provision and management in the ICN Nursing Care Continuum Framework and Competencies, ${ }^{[12]}$ these competencies are not explicitly defined in the Austrian act on nursing care. Nevertheless, Kellerer et al. ${ }^{[16]}$ showed an absolute accordance of the NPC Scale's items with the Austrian law for educational regulations for registered nurses at universities of applied sciences, where leadership and nursing development contents are clearly formulated and hence, learning outcomes and competencies are derived. ${ }^{[14]}$ The inhomogeneous experts' estimation regarding the relevance of dimension-corresponding item contents might have been representative for currently unsolved mismatches ${ }^{[34]}$ between the legally based competence areas defined by the Austrian act on nursing care on the one hand and differing national educational regulations for registered nurses on the other hand. In total 23 experts' statements indicated that requested competencies assigned in different scale dimensions may neither be necessarily required nor being able to be transformed into performance generally because of different setting-and organisation-related surrounding conditions. This estimation is congruent with Olbrich' ${ }^{[9]}$ findings regarding the determinants for the ability to become competent anyway, stating that the extent of being competent in a specific task depends on setting-specific conditions in which the availability and the need to acquire these competencies are presupposed.

Item 59 ("Do you think you have the ability to act from an environmentally conscious perspective?") has an I-CVI of 0.76 and has hence failed the predetermined cut-off. Accordingly, item related annotations underpinned the lacking relevance and the missing establishment in the qualification profile of Austrian nurses, respectively. As acting environmentally conscious might be neither formulated as a nursing competence in the ICN - Nursing Care Continuum Framework and Competencies nor quoted in Austrian law, even Dossey and Keegan ${ }^{[35]}$ emphasize growing responsibility regarding eco-mindedness as an essential part of holistic nursing.
Both quantitative (I-CVI $=0.71)$ and qualitative estimations complementary showed little relevance for the content of item 61 ("Do you think you have the ability to safeguard aesthetic aspects of the care environment?"). Expert comments criticised the unclear and unprecise meaning of the term "aesthetic", further statements either completely negated that caring about aesthetic environments was a task of nurses or at least doubted its general significance in every health care setting (i.e. "might be relevant in old people's residences but not in hospitals", FB22/I61). These estimations were replicable on the one hand, but on the other hand surprising. Firstly, the term "aesthetic" might allow varying semantic interpretations and is differently defined, relying on particular philosophical contexts. ${ }^{[36]}$ As one disregards the term's art-related meanings, more commonly used synonyms for "aesthetic" as an adjective might be i.e. "nice" or "fine". ${ }^{37]}$ From this point of view, experts' annotations seemed quite reasonable. Secondly, the more surprising aspect of stated criticism refers to the negation or at least the constraint concerning nurses' responsibility for creating aesthetic care environments, as " $[\ldots]$ aesthetic modalities in nursing practice expand [nurses'] understanding of the human condition of the clients [...] [and] the meaning of being alive in health-illness situations". ${ }^{[38]}$ Interpreting the meaning of the term this way, aesthetic awareness and thus developing competence might be essential in all nursing contexts.

The third misjudged item (78: "Do you think you have the ability to promote patient-focused nursing care in a costconscious manner?") had the lowest I-CVI of all rated items (I-CVI=0.69) and was stated as not relevant for the area of accountability of RNs. The fact, that cost-consciousness is neither explicitly pointed out as a nursing competence in the ICN - Nursing Care Continuum Framework and Competencies nor in the Austrian act on nursing care might have been a possible explanation for the poor judgement of the item content. However, cost-conscious caring is one of the central prospective issues of global health policies ${ }^{[39]}$ and could thus become a highly challenged subject regarding nursing competencies.

The S-CVI/Ave scores showed excellent content validity for the NPC Scale in total and its dimensions. Certainly, the results of complementary summative judgement could be interpreted from two different angles. From a more favourable point of view, one could see that the NPC Scale was estimated content valid with regards to its CVI/Ave scores and has the capacity to cover nursing competencies exhaustively. This is shown by summative ratings ranging from a fair to an absolute affirmation. Indeed, a more sceptical reflection could diminish this interpretation, noticing that not even three quarters $(73.5 \%)$ of all experts admitted the NPC Scale to 
absolutely cover all relevant aspects of nursing competence in Austrian context. Furthermore, only 40.8\% $(n=20 / 49)$ of the raters abundantly negated a passing lack of essential aspects of nursing competencies in the scale. Consequently, neither the claimed discharge of contentual completeness ${ }^{[22]}$ nor the adjustment from construct-irrelevant content ${ }^{[23]}$ was unconfined evident. These findings also supported the widely criticized loss of information and the risk of biasing raters' estimations by simply dichotomizing categorial variables. ${ }^{[33,40]}$

One of the strength in this study was the methodological approach of examining the theoretical construct of the scale both qualitatively and quantitatively. The mixed methods design seemed to be an appropriate method to counteract imbalanced decisions in terms of contentual eligibility and construct-specific relevance. According to Niederberger and Peter, ${ }^{[41]}$ the potential of the mixed methods design could be shown as highly valid to avoid both biases and misinterpretations in this basic step of the instrument testing procedure. Another strength in this study was the constitution of the expert sample. As the theoretical construct of nursing competence is not clearly defined, ${ }^{[8]}$ our aim was to get the NPC Scale assessed from preferably many different perspectives. Almanasreh, Moles, and Chen ${ }^{[23]}$ suggest a criterion-based sample of raters taking different qualification levels, experience, and clinical expertise into account. All experts included into the study were accurately chosen regarding these criterions, a favoured heterogeneous sample structure ensured multifaceted expert knowledge.
An interpretative-reductive method was used to analyse experts' annotations, therefore, the inductive construction of categories was potentially influenced by subjective interpretation of the researchers. Even if data analysis was counterchecked by a second independent researcher to ensure intercoder reliability, ${ }^{[32]}$ the risk of interpretative biasing might have been persisting. A further limitation is reasoned by a lack of more detailed information regarding the raters' clinical professional areas or specialized fields. This could have been useful for a deeper understanding of stated critique and the potential influence of personal clinical contexts on the estimation of relevance concerning single characteristics representing the construct of nursing competences.

\section{Conclusion}

After analyzing and interpreting the data, the German NPC Scale $^{[18]}$ cannot be recommended as a content valid instrument. Both on item- and dimension-level, there seem to be considerable contentual deficiencies in order to use the instrument to assess nursing competencies as a holistic construct in the context of RNs' professional profile or their fields of activity. In order to test the instrument on further criterions of the classical test theory, it seems appropriate to foremost carry out another testing on content validity after the removal of those three items that failed the defined cut-off-score related to the quantitative part of the study.

\section{CONFLICTS OF INTEREST Disclosure}

The authors declare that they have no competing interests.

\section{REFERENCES}

[1] Österreichisches Bundesministerium für Gesundheit. Österreichische Gesundheitsbefragung 2014 [Internet]; 2015. Available from: https://www.statistik.at/web_de/services/publikati onen/4/index . html?includePage=detailedView\&section Name $=$ Gesundheit\&pubId $=714$

[2] Schaeffer D. Professionalisierung der Pflege - Verheißung und Realität. GuS. 2011; 65(5-6): 30-7. https ://doi .org/10.5771/16 $11-5821-2011-5-6-30$

[3] Sottas B. Interprofessionelle Zusammenarbeit: Herausforderung für die Gesundheitsberufe. Biomed Austria. 2013; 06: 24-6.

[4] Reichardt C, Wernecke F, Giesler M, et al. Psychometrische Erfassung von Kompetenzen am Beispiel von Studierenden und Auszubildenden der Pflege. Pflege. 2016; 29(5): 257-65. PMid:27239742 https://doi.org/10.1024/1012-5302/a000492

[5] Mayr T, Tritscher-Archan S. Der österreichische Qualifikationsrahmen: Umsetzungsstand, Ziele und Erwartungen [Internet]. 2019 [updated 2019 Dec 16; cited 2019 Dec 16]. Available from: file:///C:/Users/kellerja/Downloads/ibw-aktue ll-nqr-umsetzungsstand-ziele-und-erwartungen.pdf

Published by Sciedu Press
[6] Cowan DT, Jenifer Wilson-Barnett D, Norman IJ, et al. Measuring nursing competence: development of a self-assessment tool for general nurses across Europe. Int J Nurs Stud. 2008; 45(6): 902-13. PMid:17451716 https://doi.org/10.1016/j.ijnurstu. 200 7.03 .004

[7] Darmann-Finck I, Glissmann G. Kompetenzdiagnostik im Berufsfeld Pflege. Pflege. 2011; 24(3): 195-204. PMid:21638259 https : //doi.org/10.1024/1012-5302/a000120

[8] Kirchhof S. Informelles Lernen und Kompetenzentwicklung für und in beruflichen Werdegängen: Dargestellt am Beispiel einer qualitativexplorativen Studie zu informellen Lernprozessen Pflegender und ihrer pädagogisch-didaktischen Implikationen für die Aus- und Weiterbildung. Münster: Waxmann; 2007. 190 p.

[9] Olbrich C. Pflegekompetenz. 3rd ed. Bern: Hogrefe; 2018. 349 p. ger.

[10] Benner PE. Stufen zur Pflegekompetenz: From novice to expert. 3rd ed. Bern: Hogrefe; 2017. 336 p.

[11] Austrian Federal Ministry for Digital and Economic Affairs. Bundesgesetz über Gesundheits- und Krankenpflegeberufe (Gesundheits- und Krankenpflegegesetz GuKG) [Internet] [cited 2019 Dec 16]. Available from: 
https://www.ris.bka.gv.at/GeltendeFassung.wxe? Abfrage=Bundesnormen\&Gesetzesnummer $=10011026$

[12] International Council of Nurses. Nursing care continuum framework and competencies. Geneva: ICN International Council of Nurses; 2008. 43 p. (ICN regulation series).

[13] Rappold E, Brandstätter E. Kompetenzmodell für Pflegeberufe in Österreich. Graz: Österreichischer Gesundheits- und Krankenpflegeverband; 2011.94 p. ger.

[14] Austrian Federal Ministry for Digital and Economic Affairs. Verordnung der Bundesministerin für Gesundheit, Familie und Jugend über Fachhochschul-Bachelorstudiengänge für die Ausbildung in der allgemeinen Gesundheits- und Krankenpflege (FHGesundheits- und Krankenpflege-Ausbildungsverordnung - FHGuKAV). BGB1. II Nr. 200/2008 [Internet] [cited 2019 Dec 16]. Available from: https://www.ris.bka.gv.at/Dokument.wxe?Abfrage =Bundesnormen\&Dokumentnummer $=$ NOR30006508

[15] Nilsson J, Johansson E, Egmar AC, et al. Development and validation of a new tool measuring nurses self-reported professional competence-the nurse professional competence (NPC) Scale. Nurse Educ Today. 2014; 34(4): 574-80. PMid:23938092 https://doi . org/10.1016/j.nedt.2013.07.016

[16] Kellerer JD, Raab I, Müller G, et al. Identifikation valider und reliabler Instrumente zur Einschätzung der Kompetenzen professionell Pflegender in Österreich. PFLEGEWISSENSCHAFT. 2018; 20(1/2): 24-38.

[17] Nilsson J, Gardulf A, Lepp M. Process of translation and adaptation of the Nurse Professional Competence (NPC) Scale. JNEP. 2015; 6(1): 100-103. https://doi.org/10.5430/jnep.v6n1p100

[18] Kellerer JD, Raab I, Müller G, et al. Übersetzung und kulturelle Adaption der Nurse Professional Competence (NPC) Scale: Die deutschsprachige NPC Skala: Ein Selbsteinschätzungsinstrument für Pflegekompetenz. PFLEGEWISSENSCHAFT. 2019; 21(1/2): 61-70.

[19] Streiner DL, Norman GR, Cairney J. Health measurement scales: A practical guide to their development and use. 5th ed. Oxford: Oxford University Press; 2015. eng. https ://doi.org/10.1093/med/97 80199685219.003 .0001

[20] Bühner M. Einführung in die Test- und Fragebogenkonstruktion. 3rd ed. München: Pearson Studium; 2011. 640 p. (PS Psychologie). ger.

[21] Waltz CF, Strickland O, Lenz ER. Measurement in nursing and health research. 4th ed. New York: Springer Pub; 2010. 492 p. eng.

[22] Moosbrugger H, Kelava A. Testtheorie und Fragebogenkonstruktion. 2nd ed. Berlin, Heidelberg: Springer-Verlag Berlin Heidelberg; 2012. (Springer-Lehrbuch). ger. PMid:23098166 https ://doi .org/10 .1007/978-3-642-20072-4

[23] Almanasreh E, Moles R, Chen TF. Evaluation of methods used for estimating content validity. Res Social Adm Pharm. 2019; 15(2): 214-21. PMid:29606610 https://doi.org/10.1016/j.saphar m.2018.03.066

[24] Bertea E, Zait A. SCALE VALIDITY IN EXPLORATORY STAGES OF RESEARCH. Management and Marketing Journal [Internet] 2013; XI(1): 38-46.
[25] Tilden VP, Nelson CA, May BA. Use of qualitative methods to enhance content validity. Nurs Res. 1990; 39(3): 172-5. https : //doi.org/10.1097/00006199-199005000-00015

[26] Wynd CA, Schmidt B, Schaefer MA. Two quantitative approaches for estimating content validity. West J Nurs Res. 2003; 25(5): 508-18. PMid:12955968 https ://doi.org/10.1177/01939459032529 98

[27] Koller I, Levenson MR, Glück J. What Do You Think You Are Measuring? A Mixed-Methods Procedure for Assessing the Content Validity of Test Items and Theory-Based Scaling. Front Psychol. 2017.

[28] Polit DF, Beck CT. The content validity index: are you sure you know what's being reported? Critique and recommendations. Res Nurs Health. 2006; 29(5): 489-97. PMid:16977646 https : //doi . org/10.1002/nur. 20147

[29] Lynn MR. Determination and quantification of content validity. Nurs Res. 1986; 35(6): 382-5. https ://doi.org/10.1097/00006199 $-198611000-00017$

[30] Polit DF, Beck CT, Owen SV. Is the CVI an acceptable indicator of content validity? Appraisal and recommendations. Res Nurs Health. 2007; 30(4): 459-67. PMid:17654487 https ://doi.org/10. 100 2/nur. 20199

[31] Mayer H. Pflegeforschung anwenden: Elemente und Basiswissen für das Studium. 4th ed. Wien: Facultas; 2015. 447 p. ger.

[32] Mayring P. Qualitative Inhaltsanalyse: Grundlagen und Techniken. 12th ed. Weinheim: Beltz; 2015. 152 p. (Beltz Pädagogik). ger.

[33] Beckstead JW. Content validity is naught. Int J Nurs Stud. 2009; 46(9): 1274-83. PMid:19486976 https ://doi.org/10.1016/j. ijnurstu. 2009.04.014

[34] Gesundheits- und Krankenpflege Evaluierung der Ausbildungsbereiche: Band II von II Ergebnisbericht (Gesamtbericht). Wien: Österreichisches Bundesinst. f. Gesundheitswesen; 2013. 167 p. ger.

[35] Dossey BM, Keegan L, Barrere CC, et al. Holistic Nursing. 7th ed. Sudbury: Jones \& Bartlett Learning LLC; 2015. 1314 p. eng.

[36] Diffey TJ. A NOTE ON SOME MEANINGS OF THE TERM 'AESTHETIC'. Brit J Aesthetics. 1995; 35(1): 61-6. https : //doi .org/ 10.1093/bjaesthetics/35.1.61

[37] yourdictionary. definitions: aesthetic [Internet] [cited 2019 Dec 17]. Available from: https://www.yourdictionary.com/aesthet ic

[38] Koithan MS. Aesthetics in nursing practice and education. Issues Ment Health Nurs. 1996; 17(6): 529-39. PMid:9052092 https : //doi.org/10.3109/01612849609006531

[39] Fitzpatrick JJ, Kazer MW. Encyclopedia of nursing research. 3rd ed. ebrary, Inc. New York, N.Y: Springer Pub; 2012. 699 p. eng.

[40] Lasarov W, Hoffmann S. Median-Split. WIST. 2017; 46(4): 11-8. https ://doi .org/10.15358/0340-1650-2017-4-11

[41] Niederberger M, Peter L. Mixed-Methods-Studien in den Gesundheitswissenschaften. Ein kritischer Überblick [Mixed methods studies in the health sciences. A critical map]. Z Evid Fortbild Qual Gesundhwes. 2018; 1339-23. ger. PMid:29605568 https ://doi .org/10 $.1016 /$ j.zefq. 2018.02 .008 